\title{
Difficulty index in extraction of impacted mandibular third molars and their post-operative complications
}

\author{
Khanal $\mathbf{P}^{1}$, Dixit $\mathbf{S}^{2}$, Singh $\mathbf{R}^{3}$, Dixit $\mathbf{P}^{4}$ \\ 'Pranaya Khanal, Lecturer; ${ }^{2}$ Siddharth Dixit, Assistant Professor; ${ }^{3}$ Rita Singh, Associate Professor; ${ }^{4}$ Punam Dixit, Assistant \\ Professor; Department of Oral and Maxillofacial Surgery, KMC Dental College, Duwakot, Bhaktapur, Nepal
}

\section{Abstract}

Background: Although the removal of impacted mandibular third molars is a common minor oral surgical procedure, the extraction of these teeth can present with certain post-operative complications. Koerner KR proposed a Difficulty Index Scale for removal of these teeth on the basis of local anatomy and radiographs, which were helpful in predicting the difficulty that would be encountered intra-operatively, as well as the post-operative complications.

Objective: To study the different post-operative complications in the removal of impacted mandibular third molars calculating their difficulty index value.

Method: A total of 119 patients, 79 females and 40 males who underwent extraction of their impacted third molars were selected over a one year period. Data were collected prospectively, according to the angulation, depth and position of the impacted mandibular third molars and their difficulty index calculated. This was further correlated with the postoperative complications encountered.

Results: Mesio-angular impaction (43.7\%), with level A (66.4\%) and Class I (70.6\%) impaction were the major type of impaction seen. The difficulty index showed that majority were in the moderately difficult category (51.2\%), with swelling and trismus seen to increase as the difficulty index value increased. Females were affected more than males, with swelling (Odds ratio 2.206) and trismus (Odds ratio 2.570) seen to be significantly more.

Conclusion: Surgical removal of impacted mandibular third molars causes post-operative complications and special care is required in their removal, especially in females. The Difficulty Index, as described by Koerner KR can be used as a tool for predicting the frequency of the post-operative complications, especially swelling and trismus.

Key words: Difficulty Index, Impaction, Post-operative complications.

\section{INTRODUCTION}

$\mathrm{T}$ The extraction of permanent mandibular third molars is the most commonly performed minor oral surgical procedure in the oral cavity, with prevalence in the range of $16.7 \%$ to $68.6 \%{ }^{1}$. A mandibular third molar can erupt in an abnormal position or can be impacted. Tooth impaction is a pathological situation in which a tooth cannot or will not erupt into its normal functioning position, unless facilitated by treatment ${ }^{2}$. Impacted Mandibular third molars cause various problems, from pericoronitis and detrimental effects on mandibular second molars, to certain types of cysts or odontogenic tumours, and primary or secondary dental crowding ${ }^{3,5}$.

\footnotetext{
Address for correspondence

Pranaya Khanal

Lecturer

Department of Oral and Maxillofacial Surgery

KMC Dental College, Duwakot, Bhaktapur, Nepal.

E-mail: pranayapop@hotmail.com
}

Studies have also shown that patients with retained impacted mandibular third molars are significantly more susceptible to mandibular angle fracture. These complications in the mandibular third molar eruption are attributable to their late formation and to the phylogenetic evolution of the mandible, which results in a lack of available space for normal eruption. Other causes for permanent third molar impaction include systemic factors like cleidocranial dysplasia, Downs syndrome, endocrine deficiencies (hypothyroidism and hypopitutarism), febrile diseases, and irradiation ${ }^{4}$ and local factors like malposed tooth germs, arch-length deficiency, supernumerary teeth, odontogenic tumours and abnormal path of eruption ${ }^{5}$.

Surgical extraction of the mandibular third molars are associated with complications, ranging from pain and swelling, trismus, secondary haemorrhage, infection, paraesthesia of the inferior alveolar nerve, to alveolar osteitis (dry socket) ${ }^{2,6}$. The occurrence of 
these complications are associated with several factors which include age, gender and health of the patient, the smoking status, use of oral contraceptives, the difficulty index of the impacted tooth and the surgical technique used along with the surgeon's experience ${ }^{7,8}$.

The purpose of this study is to evaluate the relation between difficulty index and post-operative complications during the post-operative healing period with different variables.

\section{METHODS}

A descriptive analytical study was conducted on 119 patients, 40 males and 79 females, between 18 to 35 years of age, who had either one or both mandibular third molars impacted. The study was conducted in Kathmandu Medical College and Teaching Hospital over a period of one year, from 2013 February 1 to 2014 February 1. The patients' preoperative status was recorded, along with the reason for their extraction (caries, periodontitis, or prophylactic). All the patients were advised to take an Orthopantomogram (OPG). These OPGs were reviewed by a single examiner, using an appropriate $\mathrm{X}$-ray viewer to determine the prevalence of impacted third molars in the sample, their levels of eruption; and their angulations. Then the status of the third molar was determined based on the patient's chart and the OPG. Third molars were considered impacted if it was not in functional occlusion and at the same time, its roots were fully formed. Tracing was done on a tracing paper to determine the difficulty index in the surgical extraction of the impacted tooth. The tracing consist of three lines, according to Winter ${ }^{9}$. Using these lines, the Winter's ${ }^{9}$ and the Pell and Gregory ${ }^{10}$ classification were used to document the position of the impacted tooth, and hence calculate the difficulty index.

The Difficulty Index consisted of three components:

1. Angulation of the third molar in relation to the long axis of the second molar (mesioangular, distoangular, horizontal, etc.) according to Winter's classification?

2. Depth of the third molar in relation to the occlusal plane (class A, B, C)

3. Position of the third molar in relation to the vertical ascending ramus and the distal surface of the second molar (class I, II, III) according to Pell and Gregory classification ${ }^{10}$.

The angulation of the third molar to the long axis of the second molar was measured using the method suggested by Quek et al (2003) ${ }^{11}$.
Table 1: Classification of third molar impaction by angulation (Winter's Classification)

\begin{tabular}{lc}
\hline \multicolumn{1}{|c}{ Level of impaction } & $\begin{array}{c}\text { Angulation of third molar to } \\
\text { second molar (degrees) }\end{array}$ \\
\hline Vertical impaction & 10 to -10 \\
\hline Horizontal impaction & 80 to 100 \\
\hline Distoangular impaction & -11 to -79 \\
\hline Mesioangular impaction & 11 to 79 \\
\hline Others & 111 to -80 \\
\hline Buccolingual impaction & $\begin{array}{c}\text { Any tooth oriented in a } \\
\text { buccolingual direction with } \\
\text { crown overlapping the roots }\end{array}$ \\
\hline
\end{tabular}

Table 2: Classification of third molar impaction by level of the impaction ${ }^{10}$

\begin{tabular}{cl}
\hline Level & $\begin{array}{l}\text { Definition } \\
\text { highest position of tooth in level with or above } \\
\text { the occlusal plane }\end{array}$ \\
Level & $\begin{array}{l}\text { highest position below occlusal plane, but } \\
\text { above the cervical level of second molar }\end{array}$ \\
\hline Level C & $\begin{array}{l}\text { highest position below the cervical level of } \\
\text { second molar }\end{array}$ \\
\hline
\end{tabular}

Table 3: Classification of third molar impaction by the position of the tooth ( Pell and Gregory (lassification) ${ }^{10}$

\begin{tabular}{cl} 
Position & \multicolumn{1}{c}{ Definition } \\
Class I & $\begin{array}{l}\text { sufficient space available between the } \\
\text { anterior border of the ascending ramus \& } \\
\text { distal side of second molar } \\
\text { space available between anterior border } \\
\text { of the ascending ramus and distal side } \\
\text { of second molar is less than mesio-distal } \\
\text { Width of crown of third molar }\end{array}$ \\
Class II & $\begin{array}{l}\text { third molar is totally embedded in the } \\
\text { bone because of lack of space }\end{array}$ \\
\hline
\end{tabular}

Inclusion Criteria: All the patients included in this study were 18 years and older, as growth is essentially completed by this age along with complete root formation, either being straight, curved or fused.

Exclusion Criteria: All patients having systemic conditions that might cause complications postoperatively after removal of the mandibular third molar impaction were excluded, since the scope of the present study focused only on healthy people. The systemic conditions that were taken into account were severe uncontrolled metabolic diseases (diabetes; renal diseases); leukemias; lymphomas; uncontrolled cardiac diseases (angina, myocardial infraction, 
uncontrolled hypertension); pregnancy; any bleeding disorders (haemophilia, platelet disorders); patients on anticoagulant therapy; and patients on certain drugs (corticosteroids, immunosuppressives). In addition, patients having an abnormal root configuration (dilacerated, curved, incomplete root formation) and absence of adjacent second molar were also excluded.

Ethical clearance: Ethical clearance was obtained from the institution's ethical committee. All data regarding patient identification and medical conditions were kept confidential.

\section{Table 4: Difficulty Index ${ }^{12}$}

\begin{tabular}{|c|c|c|}
\hline Classification & \multicolumn{2}{|c|}{ Difficulty index value } \\
\hline \multicolumn{3}{|l|}{ Angulation } \\
\hline Mesioangular & \multicolumn{2}{|c|}{1} \\
\hline Horizontal & \multicolumn{2}{|c|}{2} \\
\hline Transverse & \multicolumn{2}{|c|}{2} \\
\hline Vertical & \multicolumn{2}{|c|}{3} \\
\hline Distoangular & \multicolumn{2}{|c|}{4} \\
\hline \multicolumn{3}{|l|}{ Depth } \\
\hline Level A & \multicolumn{2}{|c|}{1} \\
\hline Level B & \multicolumn{2}{|c|}{2} \\
\hline Level C & \multicolumn{2}{|c|}{3} \\
\hline \multicolumn{3}{|c|}{ Ramus relationship } \\
\hline Class I & \multicolumn{2}{|c|}{1} \\
\hline Class II & \multicolumn{2}{|c|}{2} \\
\hline Class III & \multicolumn{2}{|c|}{3} \\
\hline \multirow[t]{3}{*}{ Difficulty index: } & Slightly difficult: & $3-4$ \\
\hline & Moderately difficult: & $5-7$ \\
\hline & Very difficult: & $8-10$ \\
\hline
\end{tabular}

Statistical Analysis: Data were analysed using Statistical Package for Social Sciences (SPSS) version 17.0. The age, gender, number of mandibular third molar extracted, classification of impaction, difficulty index score and complications of surgery were displayed by frequency, Odds ratio and percentage as appropriate.

\section{RESULTS}

A total of 119 impacted mandibular third molars were extracted among 40 males and 79 females. All the patients were evaluated both clinically and radiographically. The most common type of impaction, as illustrated in Table 5, according to the angulation was mesioangular (43.7\%), followed by horizontal (27.7\%), vertical (20.2\%), and distoangular (8.4\%).

As shown in Table 6, the most common position of the impacted tooth was Level A (66.4\%), and the least common was Level C (5\%). With regard to the position of the tooth, Class I was the most common position seen (70.6\%) and class III the least (2.5\%).

With regards to the post-operative complications encountered, Table 7 illustrates that there was a significant difference in the number of female and male patients presenting with swelling and trismus five days post operatively. Gender distribution of swelling and trismus showed significant difference with p-value 0.045 and 0.022 respectively. The Odds Ratio for the respective complications were 2.206 [95\% confidence interval (Cl) 1.011 - 4.811] and 1.129 [95\% Cl 1.129 - 5.850] respectively.

Table 5: Post-operative complications according to the angulation of the impacted tooth.

\begin{tabular}{|c|c|c|c|c|c|}
\hline \multirow[b]{2}{*}{ Post-operative complications } & \multicolumn{4}{|c|}{ Types of Angulation } & \multirow[b]{2}{*}{$\begin{array}{c}\text { Total } \\
n=119 \\
(100 \%)\end{array}$} \\
\hline & $\begin{array}{c}M A^{*} \\
n=52 \\
(43.7 \%)\end{array}$ & $\begin{array}{c}\text { Horizontal } \\
\qquad n=33 \\
(27.7 \%)\end{array}$ & $\begin{array}{c}\text { Vertical } \\
n=24 \\
(20.2 \%)\end{array}$ & $\begin{array}{c}\text { Distoangular } \\
\qquad=10 \\
(8.4 \%)\end{array}$ & \\
\hline Swelling & $21(40.4 \%)$ & $16(48.5 \%)$ & $16(66.7 \%)$ & 7 (70\%) & $60(50.4 \%)$ \\
\hline Pain & $31(59.6 \%)$ & $23(69.7 \%)$ & $19(79.2 \%)$ & $8(80 \%)$ & $81(68.1 \%)$ \\
\hline Trismus & $10(19.2 \%)$ & $17(51.5 \%)$ & $17(70.8 \%)$ & $6(60 \%)$ & $50(42 \%)$ \\
\hline Alveolar osteitis & $8(15.4 \%)$ & $3(9.1 \%)$ & $7(29.2 \%)$ & $5(50 \%)$ & $23(19.3 \%)$ \\
\hline Infection & $2(3.8 \%)$ & $2(6.1 \%)$ & $2(8.3 \%)$ & $1(10 \%)$ & $7(5.9 \%)$ \\
\hline Paraesthesia of IAN ${ }^{+}$ & $1(1.9 \%)$ & $1(3 \%)$ & $1(4.2 \%)$ & 0 & $3(2.5 \%)$ \\
\hline Paraesthesia of lingual nerve & $1(1.9 \%)$ & 0 & 0 & 0 & $1(0.8 \%)$ \\
\hline Secondary Haemorrhage & 0 & 0 & 0 & 0 & 0 \\
\hline Total complications & 74 & 62 & 62 & 27 & 225 \\
\hline
\end{tabular}

${ }^{*}$ Mesio-Angular, ${ }^{\dagger}$ Inferior Alveolar Nerve 
Table 6: Post-operativecomplications according to depth and position of the impacted tooth

\begin{tabular}{|c|c|c|c|c|c|c|c|c|}
\hline \multirow[b]{2}{*}{$\begin{array}{l}\text { Post-operative } \\
\text { complications }\end{array}$} & \multicolumn{4}{|c|}{ Depth } & \multicolumn{4}{|c|}{ Position } \\
\hline & $\begin{array}{c}\text { Level A } \\
n=79 \\
(66.4 \%)\end{array}$ & $\begin{array}{l}\text { Level B } \\
\qquad \begin{array}{c}n=34 \\
(28.6 \%)\end{array}\end{array}$ & $\begin{array}{c}\text { Level C } \\
\qquad \begin{array}{c}n=6 \\
(5 \%)\end{array}\end{array}$ & $\begin{array}{c}\text { Total } \\
n=119 \\
(100 \%)\end{array}$ & $\begin{array}{c}\text { Class I } \\
n=84 \\
(70.6 \%)\end{array}$ & $\begin{array}{c}\text { Class II } \\
n=32 \\
(26.9 \%)\end{array}$ & $\begin{array}{c}\text { Class III } \\
\qquad \begin{array}{c}n=3 \\
(2.5 \%)\end{array}\end{array}$ & $\begin{array}{c}\text { Total } \\
n=119 \\
(100 \%)\end{array}$ \\
\hline Swelling & 39 (49.37\%) & $17(50 \%)$ & $4(66.7 \%)$ & $60(50.4 \%)$ & 35 (41.7\%) & $24(75 \%)$ & $1(33.3 \%)$ & $60(50.4 v)$ \\
\hline Pain & $61(77.2 \%)$ & $15(44.1 \%)$ & $5(83.3 \%)$ & $81(68.1 \%)$ & $52(61.9 \%)$ & $26(81.3 \%)$ & $3(100 \%)$ & $81(68.1 \%)$ \\
\hline Trismus & $35(44.3 \%)$ & $13(38.2 \%)$ & $2(33.3 \%)$ & $50(42 \%)$ & $29(34.5 \%)$ & $18(56.3 \%)$ & $3(100 \%)$ & $50(42 \%)$ \\
\hline Alveolar osteitis & $18(22.8 \%)$ & $3(8.8 \%)$ & $2(33.3 \%)$ & $23(19.3 \%)$ & $14(16.7 \%)$ & $9(28.1 \%)$ & 0 & $23(19.3 \%)$ \\
\hline Infection & $4(5 \%)$ & $2(5.8 \%)$ & $1(16.7 \%)$ & 7 (5.9\%) & $3(3.6 \%)$ & $4(12.5 \%)$ & 0 & $7(5.9 \%)$ \\
\hline Paraesthesia of IAN* & $1(1.3 \%)$ & $1(2.9 \%)$ & $1(16.7 \%)$ & $3(2.5 \%)$ & $1(1.2 \%)$ & $1(3.1 \%)$ & $1(33.3 \%)$ & $3(2.5 \%)$ \\
\hline $\begin{array}{l}\text { Paraesthesia of lingual } \\
\text { nerve }\end{array}$ & $1(1.3 \%)$ & 0 & 0 & $1(0.8 \%)$ & $1(1.2 \%)$ & 0 & 0 & $1(0.8 \%)$ \\
\hline $\begin{array}{l}\text { Secondary } \\
\text { Haemorrhage }\end{array}$ & 0 & 0 & 0 & 0 & 0 & 0 & 0 & 0 \\
\hline Total complications & 159 & 51 & 15 & 225 & 135 & 82 & 8 & 225 \\
\hline
\end{tabular}

*Inferior Alveolar Nerve

Table 7: Gender differentiation and post-operative complications

\begin{tabular}{|c|c|c|c|c|c|c|}
\hline \multirow{2}{*}{ Variables } & & \multicolumn{2}{|c|}{ Sex } & \multirow{2}{*}{ p-value } & \multirow{2}{*}{ Odds Ratio } & \multirow{2}{*}{$95 \%$ Confidence Interval } \\
\hline & & Female & Male & & & \\
\hline \multirow{2}{*}{ Swelling } & Yes & 45 & 15 & \multirow{2}{*}{0.045} & \multirow{2}{*}{2.206} & \multirow{2}{*}{$1.011-4.811$} \\
\hline & No & 34 & 25 & & & \\
\hline \multirow{2}{*}{ Pain } & Yes & 58 & 23 & \multirow{2}{*}{0.079} & \multirow{2}{*}{2.041} & \multirow{2}{*}{$0.916-4.549$} \\
\hline & No & 21 & 17 & & & \\
\hline \multirow{2}{*}{ Trismus } & Yes & 39 & 11 & \multirow{2}{*}{0.022} & \multirow{2}{*}{2.570} & \multirow{2}{*}{$1.129-5.850$} \\
\hline & No & 40 & 29 & & & \\
\hline \multirow{2}{*}{ Alveolar osteitis } & Yes & 16 & 7 & \multirow{2}{*}{0.719} & \multirow{2}{*}{1.197} & \multirow{2}{*}{$0.448-3.200$} \\
\hline & No & 63 & 33 & & & \\
\hline \multirow{2}{*}{ Infection } & Yes & 3 & 4 & \multirow{2}{*}{0.174} & \multirow{2}{*}{0.355} & \multirow{2}{*}{$0.076-1.671$} \\
\hline & No & 76 & 36 & & & \\
\hline
\end{tabular}

$\mathrm{p}$ value calculated by chi-square test.

Table 8: Difficulty Index and post-operative complications

\begin{tabular}{|c|c|c|c|c|c|}
\hline \multirow{2}{*}{ Variables } & & \multicolumn{3}{|c|}{ Difficulty Index } & \multirow{2}{*}{ p-value } \\
\hline & & Less difficult & Moderately difficult & Very difficult & \\
\hline \multirow{2}{*}{ Swelling } & Yes & 18 & 41 & 1 & \multirow{2}{*}{0.000} \\
\hline & No & 39 & 20 & 0 & \\
\hline \multirow{2}{*}{ Pain } & Yes & 34 & 46 & 1 & \multirow{2}{*}{0.147} \\
\hline & No & 23 & 15 & 0 & \\
\hline \multirow{2}{*}{ Trismus } & Yes & 12 & 38 & 0 & \multirow{2}{*}{0.000} \\
\hline & No & 45 & 23 & 1 & \\
\hline \multirow{2}{*}{ Alveolar osteitis } & Yes & 6 & 17 & 0 & \multirow{2}{*}{0.052} \\
\hline & No & 51 & 44 & 1 & \\
\hline \multirow{2}{*}{ Infection } & Yes & 1 & 6 & 0 & \multirow{2}{*}{0.170} \\
\hline & No & 56 & 55 & 1 & \\
\hline \multirow{2}{*}{ Paraesthesia of IAN* } & Yes & 0 & 3 & 0 & \multirow{2}{*}{0.410} \\
\hline & No & 56 & 58 & 1 & \\
\hline
\end{tabular}

*Inferior Alveolar Nerve 
Table 8 shows the relationship between the difficulty index and the post-operative complications encountered. Apart from swelling and trismus, other complications like pain, alveolar osteitis, infection and paraesthesia of the inferior alveolar nerve did not show significant distribution among different categories of difficulty index. Swelling and trismus were seen to increase significantly in frequency as the difficulty index value increased, with the most number of cases seen in moderately difficult cases.

\section{DISCUSSION}

Since the extraction of mandibular third molars that are impacted or erupting in an abnormal position has been the first line of treatment ${ }^{1,2,6}$, an assessment of the surgical difficulty in third molar surgery is fundamental to forming an optimal treatment plan in order to minimize the complications associated with it. These surgical extractions are commonly performed both for prophylactic as well as for therapeutic purposes. Although their removal is a common minor oral surgical procedure, there are complications associated with it, like pain, swelling, trismus, alveolar osteitis and paraesthesia of the inferior alveolar nerve ${ }^{6,7}$.

The positions of the impacted mandibular third molars and the post-operative complications have been studied in various populations. A study among the Jordanian population ${ }^{13}$ found that vertical type of angulation was the most common (61.4\%) and mesioangular type was only $18.1 \%$. However, studies among Chinese $(80 \%)$ and Korean populations (46.5\%) showed that mesioangular type of impaction was the most frequently seen ${ }^{11}$. In this present study too, the mesioangular type was the commonly extracted tooth (43.7\%).

Assessing the width and depth of impaction with reference to the ascending ramus and occlusal plane of the second molar, it was found that the greatest percentage was seen in level A (66.4\%) and class I (70.6\%). In a Nigerian population, the commonest position was seen as Level A (31.9\%) and Class II position $(60.8 \%)^{14}$. Monaco also reported a similar finding where the highest percentage of impacted molar position was Level A (56.2\%) and Class II (63\%) among Italians ${ }^{15}$. The findings of the present study showed similarity in the depth of the impacted tooth (level A) with most other reports, which indicated that most impacted third molars had the highest portion at the occlusal level.

Since there are several factors which determine the occurrence of the post-operative complications, it is difficult to evaluate all the factors as there is a large variation among the patients and also difficulty to establish a study design. In the present study, radiographs, especially orthopantomograms were taken in all the 119 patients and only the three factors; angulation, depth and position were taken into account. In this context, however, few studies have attempted to analyse several factors that determine the surgical difficulty and the factors that determine the postoperative complications ${ }^{16-18}$.

The orthopantomograms were used in the present study along with the Winters lines ${ }^{9}$, that is used to determine the depth of the impacted tooth in the bone. This method, proposed by Winter was further supported and expanded by Macgregor in $1985^{19}$, where he used the WHARFE assessment to determine the difficulty index for the impacted tooth. This assessment included the Winters lines along with other factors. In the study, the Pell and Gregory's assessment of difficulty, also based on the dental radiographic features, has been used to further substantiate the Winter's method of assessment.

The present study has divided the difficulty index scores into three categories; less difficult, moderately difficult and very difficult for each post-operative complication seen. Most of the patients (51.2\%) had moderately difficult index scores. Among the less and the moderately difficult categories, it is seen that pain, swelling and trismus were the most common complications seen. Alveolar osteitis, a less commonly seen complication but an important one, were seen for both the less and moderately difficult categories. The reported incidence of alveolitis varies widely, from as low as $0.5 \%$ to as high as $68.4 \%^{20,21}$, but most studies indicate a rate between $5 \%$ and $10 \%$. In their review article, Precious et al. suggested that, despite surgical ability and strict operative protocol, the hypothetical rate of alveolitis was between one and five percent. Diagnostic criteria, which might vary from author to author, might partly explain this variation. The incidence in the current study was lower in the less difficult cases (5\%) but was more in moderately difficult cases (14.3\%).

Table 7 shows the occurrence of the post-operative complications among males and females. Here, swelling and trismus were seen to be of significance while the other complications were not significant. Swelling was seen $56.9 \%$ of the females, which was around 2.206 times that of the males $(37.5 \%)$ as determined by the Odds ratio. Furthermore, trismus was also seen to occur more in females $(49.36 \%)$ than in males $(27.5 \%)$. This could be attributed to the females being more susceptible to 
complications than males, due to factors like use of oral contraceptives ${ }^{22,23}$.

Table 8 shows that there is a significant increase in the number of patients who presented with swelling and trismus, as the difficulty index value increased, indicating that, the more the difficulty index value, the higher the chances of occurrence of swelling $\left(\chi^{2}: 15.959\right.$; $p$ value 0.000 ) and trismus ( $\chi^{2}: 21.30 ; p$ value 0.000 ). This can be contributed by several other factors like the age, gender, the configuration of the roots, and the length of time taken for the removal of the tooth, and whether osteotomy was performed for the extraction ${ }^{17}$.

\section{CONCLUSION}

This study allowed an evaluation of the difficulty index, as proposed by Koerner KR, and the incidence of post- operative complications associated with extraction of impacted mandibular third molars. Women were seen to have more complications than males, especially swelling and trismus. No specific factor was identified to explain this difference between the sexes.

The rate of post-operative complications with the increase in the Difficulty Index were significant only for the post-operative complications like swelling and trismus. Therefore, it is recommended that, apart from the Difficulty Index score, other factors which can determine the difficulty index of the impacted tooth being extracted, like the WHARFE assessment should also be taken into account, along with the length of time for removal of the teeth, the flap designs, the root anatomy and the surgeon's experience.

\section{REFERENCES}

1. Dachi SF, Howell FV. A survey of 3874 routine full mouth radiographs. A study of impacted teeth. Oral Surg. 1961;14:1165-9.

2. American Association of Oral and Maxillofacial Surgery. Impacted teeth. Oral Health. 1998;88:31-2.

3. Chiapasco M, DeCicco L, Marrone G. Side effects and complications associated with third molar surgery. Oral Surg Oral Med Oral Pathol. 1993;76(4);412-20.

4. Bishara SE. Impacted Maxillary canines: a review. Am J Orthod Dentofacial Orthop. 1992;101(2):159-71.

5. Raghoebar GM, Boering G, Vissink A, Steganga B. Eruption disturbances of permanent molars: a review. J Oral Pathol Med. 1991;20(4):159-66.

6. Sisk AL, Hammer WB, Shelton DW, Joy ED Jr. Complications following removal of impacted third molars; the role of the experience of the surgeon. J Oral Maxillofac Surg. 1986;44(11):855-9.

7. Bui Ch, Seldin EB, Dodson TB. Types, frequencies and risk factors for complications after third molar extraction. J Oral Maxcillofac Surg. 2003;61(12);1379-89.

8. Lopes V, Mumenya R, Feinmann C, Harris M. Third molar surgery; an audit of the indications for surgery, post-operative complaints and patient satisfaction. Br J Oral Maxillofac Surg. 1995;33(1):335.

9. Winter GB. Principles of exodontias as applied to the impacted mandibular third molar. St. Louis (MO): American Medical Book co; 1926.

10. Pell, Gregory GT. Impacted Mandibular third molars: classification and modified technique for removal. Dent Dig. 1993;39:330-8.

11. Quek SL, Tay CK, Tay KH, Joh SL, Lim KC. Pattern of third molar impaction in a Singapore Chinese population: a retrospective radiographic survey. Int J Oral Maxillofac Surg. 2003;32(5):548-52.

12. Koerner KR. The removal of impacted third molars - Principles and procedures. Dent Clin North Am. 1994;38:255-78.

13. Bataineh $A B$, Albashaireh ZS, Hazza'a AM. The surgical removal of mandibular third molars: a study in decision making. Quintessence Int. 2002;33(8):613-7.

14. Obiechina AE, Arotiba JT, Fasola AO. Third molar impaction: evaluation of the symptoms and pattern of impaction of mandibular third molar teeth in Nigerians. Odontostomatol Trop. 2001;24(93):22-5.

15. Monaco G, Montevecchi M, Bonetti GA, Gatto MR, Checchi L. Reliability of panoramic radiography in evaluating the topographic relationship between the mandibular canal and impacted third molars. J Am Dent Assoc. 2004;135(3):312-8.

16. Yuasa $H$, Kawai $T$, Sugiura M. Classification of Surgical Difficulty in extracting impacted third molars. Br J Oral Maxillofac Surg. 2002;40:26-31.

17. Renton T, Smeeton N, McGurk M. Factors predictive of difficulty of mandibular third molar surgery. $\mathrm{Br}$ Dent J. 2001;190:607-10.

18. Wathson R, Carvalho F, Cavalcanti B. Assessment of Factors Associated With Surgical Difficulty During Removal of Impacted Lower Third Molars. J Oral Maxillofac Surg. 2011;69:2714-21.

19. MacGregor AJ. The impacted lower wisdom tooth. New York: Oxford University Press; 1985. 
20. Houston JP, McCollum J, Pietz D, Schneck D. Alveolar osteitis: a review of its etiology, prevention, and treatment modalities. Gen Dent. 2002;50(5):457-65.

21. Sorensen DC, Preisch JW. The effect of tetracycline on the incidence of post-extraction alveolar osteitis. J Oral Maxillofac Surg. 1987;45:1029-33.
22. Catellani JE, Harvey S, Erickson SH, Cherkin D. Effect of oral contraceptive cycle on dry socket (localized alveolar osteitis). J Am Dent Assoc. 1980;101(5):77780.

23. Houston JP, McCollum J, Pietz D, Schneck D. Alveolar osteitis: a review of its etiology, prevention, and treatment modalities. Gen Dent. 2002;50(5):457-65. 